\title{
Quadratic Prediction Models for the Performance Comparison of a Marine Engine Fuelled with Biodiesels B5 and B20
}

\author{
Chedthawut Poompipatpong ${ }^{1,2}$ \\ ${ }^{1}$ Automotive Eco-Energy and Industrial Product Standard Research Center, King Mongkut's University of Technology North Bangkok, \\ 1518 Pracharat 1, Wongsawang, Bangsue, 10800 Bangkok, Thailand \\ ${ }^{2}$ Department of Automotive Engineering Technology, King Mongkut's University of Technology North Bangkok, \\ 1518 Pracharat 1, Wongsawang, Bangsue, 10800 Bangkok, Thailand
}

Correspondence should be addressed to Chedthawut Poompipatpong; chedthawutp@kmutnb.ac.th

Received 31 May 2014; Revised 2 September 2014; Accepted 16 September 2014; Published 30 September 2014

Academic Editor: Z. X. Guo

Copyright (C) 2014 Chedthawut Poompipatpong. This is an open access article distributed under the Creative Commons Attribution License, which permits unrestricted use, distribution, and reproduction in any medium, provided the original work is properly cited.

According to Thailand's renewable energy development plan, biodiesel is one of the interesting alternative energies. In this research, biodiesels B5 and B20 are tested in a marine engine. The experimental results are then compared by using three different techniques including (1) the conventional technique, (2) average of the point-to-point comparisons, and (3) a comparison by using quadratic prediction models. This research aims to present the procedures of these techniques in-depth. The results show that the comparison by using quadratic prediction models can accurately predict ample amounts of results and make the comparison more logical. The results are compatible with those of the conventional technique, while the average of the point-to-point comparisons shows diverse results. These results are also explained on the fuel property basis, confirming that the quadratic prediction model and the conventional technique are practical, but the average of the point-to-point comparison technique presents an inaccurate result. The benefit of this research shows that the quadratic prediction model is more flexible for future science and engineering experimental design, thus reducing cost and time usage. The details of the calculation, results, and discussion are presented in the paper.

\section{Introduction}

Alternative energy is one of the most interesting issues in the current situation. Biodiesel, diesohol, and pyrolysis oil have been improved and are replacing the usage of conventional automotive diesel fuel because some of them show ecological benefits and some economic benefits. An important topic of the investigation of alternative fuels is the differences of engine performance and emission concentrations $[1,2]$. The experimental results of conventional fuel are the reference values. Then, the results of alternative fuels are compared to the reference values. The literature generally reports these differences in units of percentage for ease of understanding $[3,4]$.

For example, in order to compare engine performance when operated with two different fuels, the output performances over the whole test condition of each fuel are averaged and then these values are compared. This process is done by research $[5,6]$ and is called the "conventional technique" in this research. This conventional comparison technique is straightforward and acceptable. However, the weak point is that the number of experimentations is limited in many scientific and engineering researches due to the cost and time consumption. Hence, this technique works only on experimental results and it cannot be assured that the number of experimentations will be sufficient to be the representative of the entire engine performance and emission.

This research experimentation was done on a six-cylinder marine diesel engine fuelled with biodiesels B5 and B20, since biodiesel B5 is currently used in Thailand and the official government plan is approaching biodiesel B20. Since the objective of this research was to present the details of three different comparison techniques, engine torque was selected as the example throughout the paper because it is one of the most important diesel engine parameters [7]. The most outstanding benefits of this research are that (1) the difference of using biodiesels B5 and B20 is depicted in terms of engine performance and (2) the details of three comparison 


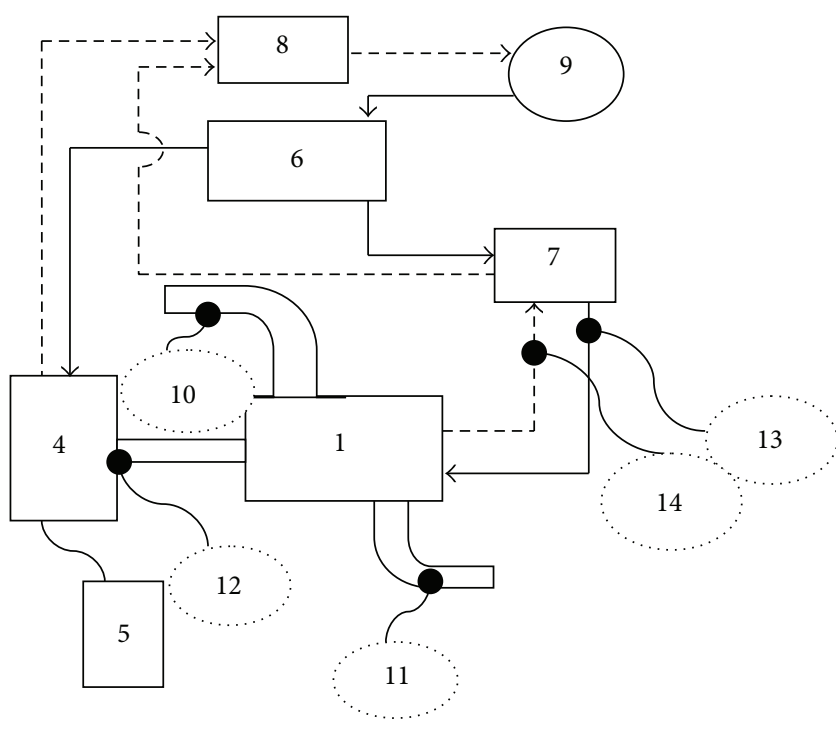

(1) Diesel engine

(2) Intake manifold

(3) Exhaust manifold

(4) Engine dynamometer

(5) Dynamometer controller

(6) Water supply tank

(7) Engine coolant supply tank

(8) Hot water reservoir

(9) Cooling tower

(10) Airflow meter

(11) Exhaust gas temperature sensor

(12) Engine speed sensor

(13) Inlet coolant temperature

(14) Outlet coolant temperature

techniques are presented. This will assist researchers in selecting the most appropriate comparison technique for reliable and accurate results in the future.

\section{Experimental Setup and Engine Testing}

In order to accomplish the main objective of this research, a GARDNER 6-cylinder 10,450 cc marine diesel engine was installed on a Clayton water brake dynamometer, which supplied the engine load. The fuel consumption was measured on a geometric basis using a digital scale and a stop watch. A KIMO CP200 and a Debimo airflow measuring blade were attached at the intake manifold for the airflow measurement. Thermocouples were connected at several positions in order to collect the raw data. A closed-loop water cooling system with a cooling tower was utilized. The engine temperature was controlled by a coolant temperature controller. The diagram of the experimental setup is shown in Figure 1.

The experimentation was conducted at full load condition over the engine speed range between 1000 and $1400 \mathrm{rpm}$, with an interval of $100 \mathrm{rpm}$. Thirty raw data were recorded for every test condition and the average values were presented. The engine was first operated with biodiesel B5 for experimentation. After the test, the engine was switched to biodiesel B20 and run for a while in order to flush out the biodiesel B5 from the fuel line and injection system. Finally, biodiesel B20 was tested at exactly the same condition. The biodiesels B5 and B20 in this research were supplied by the Petroleum Authority of Thailand Public Company Limited

TABLE 1: Fuel properties.

\begin{tabular}{lcc}
\hline Properties & $\begin{array}{c}\text { Regulation for } \\
\text { biodiesel B5 }\end{array}$ & $\begin{array}{c}\text { Biodiesel B20 from } \\
\text { PTT }\end{array}$ \\
\hline Cetane number & $\geq 50$ & 57.34 \\
Specific gravity & From 0.81 to 0.87 & 0.8408 \\
Viscosity at $40^{\circ} \mathrm{C}$ & From 1.8 to 4.1 & 3.774 \\
Flash point $\left({ }^{\circ} \mathrm{C}\right)$ & $\geq 52$ & 79.0 \\
Pour point $\left({ }^{\circ} \mathrm{C}\right)$ & $\leq 10$ & 9 \\
Water and sediment & $\leq 0.05$ & $<0.005$ \\
(\% vol. $)$ & 41238.55 & 45233.33 \\
Heating value $(\mathrm{J} / \mathrm{g})$ & &
\end{tabular}

(PTT). The fuel properties conformed to the regulations of the Department of Energy Business, Thailand Ministry of Energy. The details of the fuel specifications are shown in Table 1.

\section{Comparison Techniques and the Results}

Raw data were collected from the engine experiment and were then analyzed and compared by using three different comparison techniques. The results of every technique were reported in percentage units (\%) because this method is more reasonable and comparable than when the information is presented in raw data. Nevertheless, there are several methods that are used to calculate percentages and which provide dissimilar results. This paper presents the details of three methods, including one conventional method and two new comparison methods, which are (1) "the comparison of the average values (conventional technique)," (2) "the average of the point-to-point comparisons (the new technique 1)," and (3) "the comparison by applying quadratic prediction model (the new technique 2)." It is also important to note that the output torque was selected as the representative of the engine performance throughout the paper.

3.1. Methodology of Conventional Technique: A Comparison of the Average Values. This technique is the simplest and most commonly used comparison technique. It consists of only two main steps, which are the averaging of the output data and then the average data of biodiesel B20 is compared to that of biodiesel B5 (reference value) by using the percentage deviation method (PD). This method is called "averaging before comparing," or "the comparison of the average values." The detailed methodology is shown in Figure 2.

Figure 3 shows that biodiesel B5 produces slightly higher output torque than that of biodiesel B20. All of the experimental data in Figure 5 are also summarized in Table 2. The average output torques over the speed conditions of 1000 to $1400 \mathrm{rpm}$ were $549.50 \mathrm{Nm}$ and $508.06 \mathrm{Nm}$ for biodiesels B5 and B20, respectively. The difference was basically determined using percentage deviation method. The comparison results using the conventional technique show that the engine fuelled with biodiesel B20 generates 7.54\% lower torque than that of the engine fuelled with biodiesel B5. 


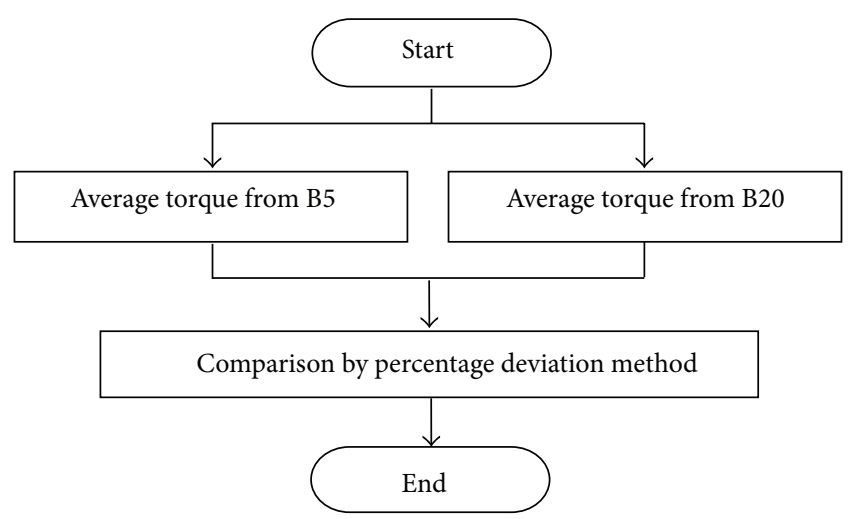

Figure 2: Methodology of the conventional technique.

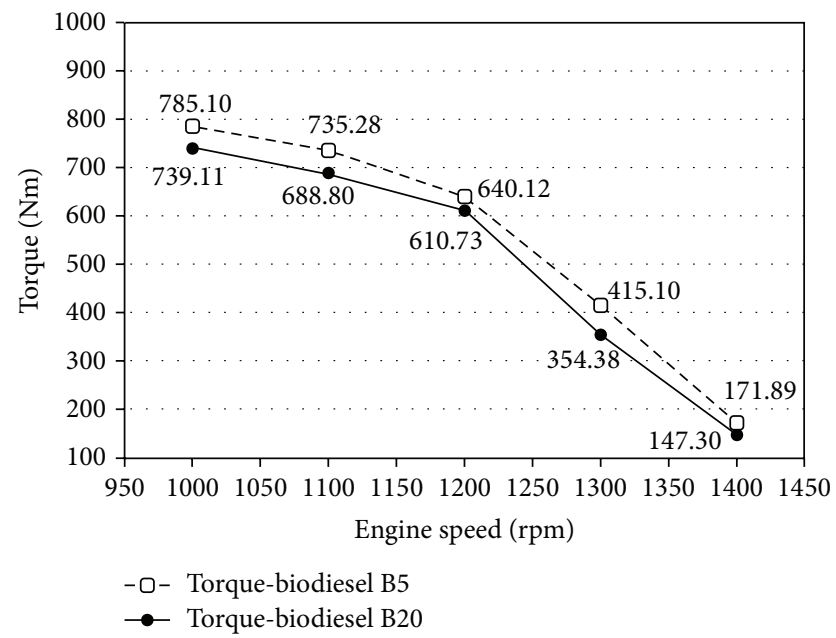

FIGURE 3: Experimental results.

3.2. Methodology of the New Technique 1: The Average of the Point-to-Point Comparisons. The purpose of presenting this technique in this paper is to depict its advantage. Pointto-point comparison reports a set of detailed results for researchers. This technique is very similar to the conventional technique. The only difference is in the sequence between averaging and comparing. The two important steps of this technique are, first, the point-to-point comparison between biodiesel B5 and biodiesel B20. Then, the results of the point-to-point comparisons are averaged. This means that this technique employs the "comparing before averaging" method. This method is more complicated especially when there are many experimental data. The methodology of this technique is presented in Figure 4.

Table 3 shows that the output torques of biodiesels B5 and B20 were compared in every tested condition. Therefore, the process included five pair-wise comparisons. Finally, the results were averaged. It can be concluded concerning the new technique 1 that the engine fuelled with biodiesel B20 produces $9.14 \%$ lower torque than that of the engine fuelled with biodiesel B5.

3.3. Methodology of the New Technique 2: The Comparison by Using Quadratic Prediction Model. According to the

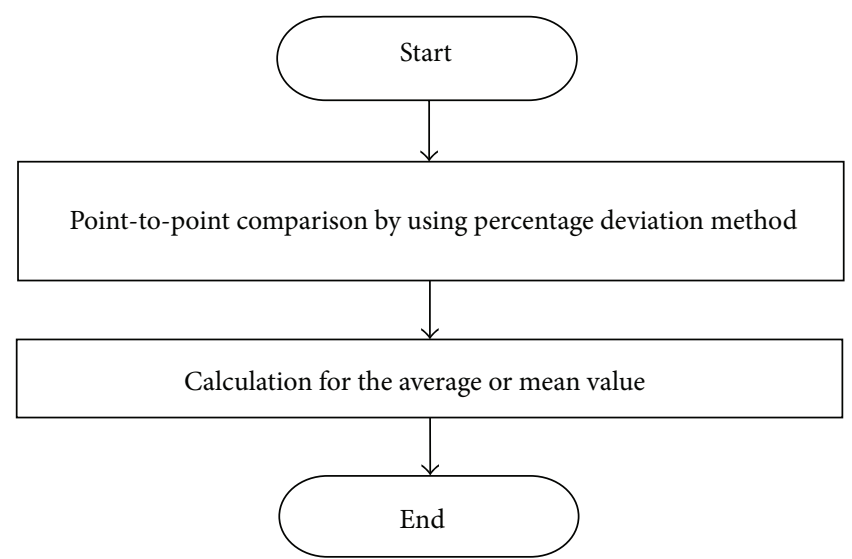

Figure 4: Methodology of the new technique 1.

TABLE 2: The comparison result using the conventional technique.

\begin{tabular}{lcc}
\hline Speed $(\mathrm{rpm})$ & \multicolumn{2}{c}{ Output torque $(\mathrm{Nm})$} \\
& $\begin{array}{c}\text { Biodiesel B5 } \\
\text { (reference) }\end{array}$ & Biodiesel B20 \\
\hline 1000 & 785.10 & 739.11 \\
1100 & 735.28 & 688.80 \\
1200 & 640.12 & 610.73 \\
1300 & 415.10 & 354.38 \\
1400 & 171.89 & 147.30 \\
\hline Average & 549.50 & 508.06 \\
\hline & $\mathrm{PD}=\frac{(508.06-549.50)}{549.50} \times 100 \%=$ & $-7.54 \%$ \\
\hline
\end{tabular}

experimentation, all of the calculations using conventional techniques and the new technique 1 were based on only five levels of speed: 1000, 1100, 1200, 1300, and $1400 \mathrm{rpm}$. It is understandable that only five levels of speed cannot be representative of all of the values between 1000 and $1400 \mathrm{rpm}$, and this limitation puts the comparison results in doubt. This is the reason why the new technique 2 is relatively different from the previous techniques-it is more complex but also more flexible and reliable. The procedure is shown in Figure 5. This technique will help researchers in overcoming this limitation by systematically integrating four basic mathematical steps, as follows.

3.3.1. Mathematical Modelling and Quadratic Prediction Model Plot. Engine torque is modelled as a function of engine speed $(x)$. The second-order quadratic model is normally suggested since it is sufficient to fit the data in most cases [8-10] without overfitting [11]. The quadratic model contains a squared term $\left(x^{2}\right)$, a linear term $(x)$, and a constant term (c), which have coefficients of $a$ and $b$ as shown in (1). At the end of this step, two quadratic prediction models were generated. One was the representative of biodiesel B5 and the other was of biodiesel B20. They are shown in (2) and (3), respectively. The prediction curves are also presented in Figure 6. Consider

$$
\text { Torque }=a x^{2}+b x+c,
$$


TABle 3: The comparison result by using the new technique 1.

\begin{tabular}{lccc}
\hline \multirow{2}{*}{ Speed $(\mathrm{rpm})$} & \multicolumn{2}{c}{ Output torque $(\mathrm{Nm})$} & Point-to-point percentage deviation \\
\hline 1000 & Biodiesel B5 (reference) & Biodiesel B20 & $-5.86 \%$ \\
1100 & 785.10 & 739.11 & $-6.32 \%$ \\
1200 & 735.28 & 688.80 & $-4.59 \%$ \\
1300 & 640.12 & 610.73 & $-14.63 \%$ \\
1400 & 415.10 & 354.38 & $-14.31 \%$ \\
\hline & 171.89 & 147.30 & $-9.14 \%$ \\
\hline
\end{tabular}

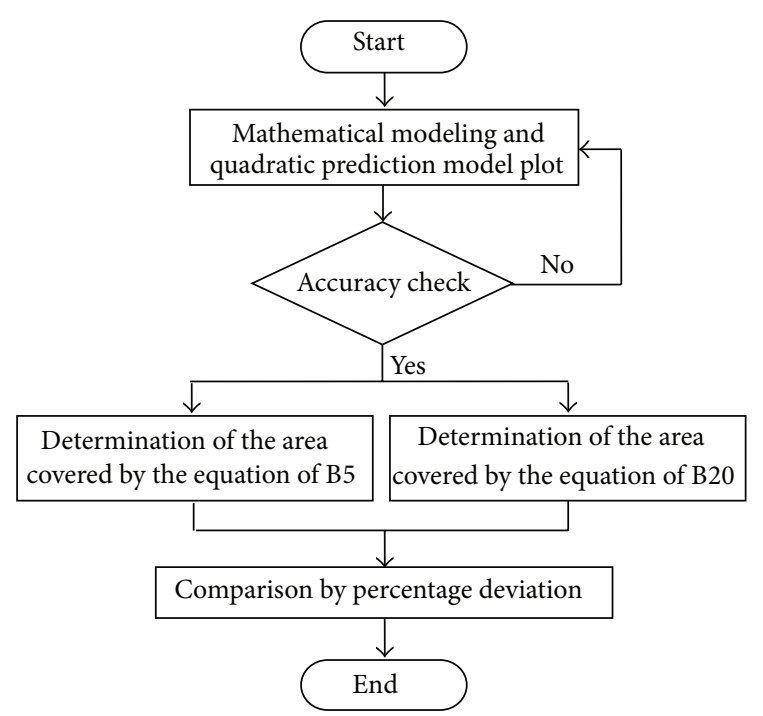

Figure 5: Methodology of the new technique 2.

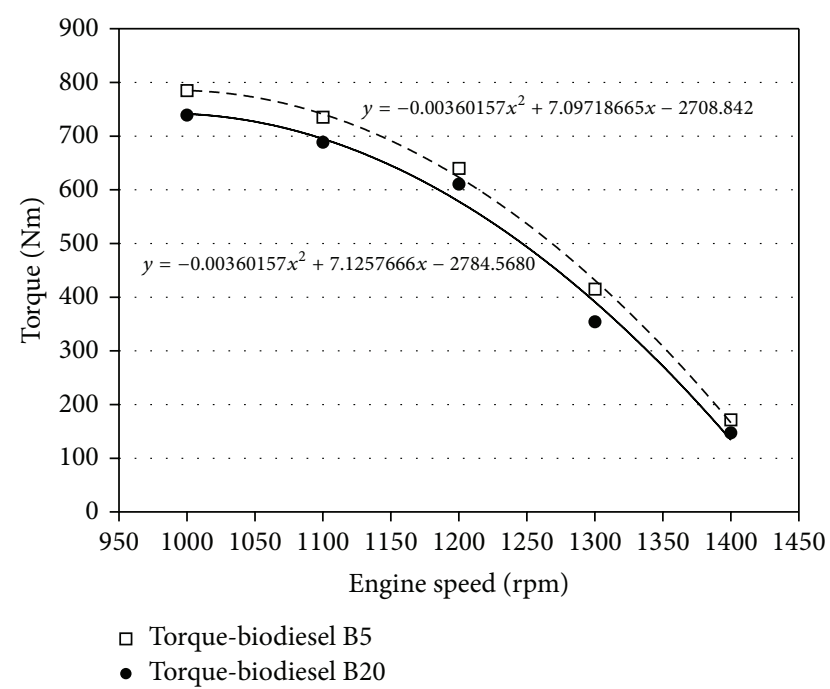

FIgURE 6: The plots of the quadratic prediction models.

Torque $_{B 5}=-0.00360157 x^{2}+7.09718665 x+2708.842$,

Torque $_{B 20}=-0.00360157 x^{2}+7.1267666 x+2784.568$.
3.3.2. Accuracy Check. Each level of speed was placed into the equations and the predicted values were calculated. The differences between the measured and predicted values are the errors which can identify the accuracies of the generated quadratic models. Literature $[12,13]$ suggests that mean absolute percentage error (MAPE) is generally used because it is a unit-free and is an easily understandable method. The MAPE is defined in (4). One has

$$
\text { MAPE }=\frac{1}{n} \sum_{i=1}^{n} \frac{\mid \text { measured value }- \text { predicted value } \mid}{\text { measured value }} \times 100 \text {. }
$$

Each level of engine speed was placed into (2) and the predicted torque of biodiesel B5 was calculated. The results are shown in Table 4 . The same process was also carried out with (3) and the predicted torque of biodiesel B20 is shown in Table 5. Tables 4 and 5 also present the existing errors. It was found that the mean absolute percentage errors were $1.95 \%$ and $5.38 \%$ for (2) and (3), respectively. An MAPE of lower than $10 \%$ confirmed that both quadratic models were very accurate (excellent prediction) [13-15].

Moreover, Tables 4 and 5 show the mean percentage error (MPE) of $-0.083 \%$ and $-0.664 \%$, respectively. These values indicate that the predicted values were on average $0.083 \%$ and $0.664 \%$ lower than the measured values. As a result, the holistic accuracies of the generated quadratic prediction models were $99.917 \%$ and $99.336 \%$, respectively.

3.3.3. Determination of Area Covered by the Quadratic Model. After the quadratic models were validated, they were used as representatives of the engine torque for biodiesels B5 and B20 operations. These models can accurately predict numerous results within the testing range. Then, the areas covered by both quadratic prediction curves were determined using the definite integration method between 1000 and $1400 \mathrm{rpm}$. The results were determined as follows:

$$
\begin{gathered}
\text { Area }_{B 5}=\int_{1000}^{1400}\left(-0.00360157 x^{2}+7.09718665 x\right. \\
-2708.842) d x \\
\text { Area }_{B 5}=229399.86
\end{gathered}
$$


TABLE 4: Accuracy check of the quadratic prediction model for biodiesel B5.

\begin{tabular}{|c|c|c|c|c|c|}
\hline \multirow{2}{*}{ Speed (rpm) } & \multicolumn{2}{|c|}{ Torque-B5 (Nm) } & \multicolumn{3}{|c|}{ Error } \\
\hline & Measured value & Predicted value & $(\mathrm{Nm})$ & Percentage & Absolute percentage \\
\hline 1000 & 785.10 & 786.77 & 1.67 & $0.21 \%$ & $0.21 \%$ \\
\hline 1100 & 735.28 & 740.16 & 4.88 & $0.66 \%$ & $0.66 \%$ \\
\hline 1200 & 640.12 & 621.52 & -18.60 & $-2.91 \%$ & $2.91 \%$ \\
\hline 1300 & 415.10 & 430.85 & 15.75 & $3.79 \%$ & $3.79 \%$ \\
\hline 1400 & 171.89 & 168.14 & -3.75 & $-2.18 \%$ & $2.18 \%$ \\
\hline \multicolumn{3}{|c|}{ Average or mean } & 0.008 & $-0.083 \%$ & $1.95 \%$ \\
\hline \multicolumn{3}{|c|}{ Interpretation } & & $99.917 \%$ accuracy & Excellent prediction \\
\hline
\end{tabular}

TABLE 5: Accuracy check of the quadratic prediction model for biodiesel B20.

\begin{tabular}{|c|c|c|c|c|c|}
\hline \multirow{2}{*}{ Speed (rpm) } & \multicolumn{2}{|c|}{ Torque-B20 (Nm) } & \multicolumn{3}{|c|}{ Error } \\
\hline & Measured value & Predicted value & $(\mathrm{Nm})$ & Percentage & Absolute percentage \\
\hline 1000 & 739.11 & 739.63 & 0.52 & $0.07 \%$ & $0.07 \%$ \\
\hline 1100 & 688.80 & 695.88 & 7.08 & $1.03 \%$ & $1.03 \%$ \\
\hline 1200 & 610.73 & 580.09 & -30.64 & $-5.02 \%$ & $5.02 \%$ \\
\hline 1300 & 354.38 & 392.28 & 37.90 & $10.69 \%$ & $10.69 \%$ \\
\hline 1400 & 147.30 & 132.43 & -14.87 & $-10.10 \%$ & $10.10 \%$ \\
\hline \multicolumn{3}{|c|}{ Mean } & 0.004 & $-0.664 \%$ & $5.381 \%$ \\
\hline \multicolumn{4}{|c|}{ Interpretation } & $99.336 \%$ accuracy & Excellent prediction \\
\hline
\end{tabular}

$$
\begin{gathered}
\text { Area }_{B 20}=\int_{1000}^{1400}\left(-0.00360157 x^{2}+7.1267666 x\right. \\
-2784.568) d x \\
\text { Area }_{B 20}=212827.83
\end{gathered}
$$

3.3.4. The Comparison of Engine Torque. The difference between biodiesel B5 and B20 was then determined by the percentage deviation method. This is shown in (6). The comparison results show that the engine fuelled with biodiesel B20 produces $7.22 \%$ lower torque than that of the engine fuelled with biodiesel B5. Consider

$$
\begin{gathered}
\mathrm{PD}=\frac{(212827.83-229399.86)}{229399.86} \times 100 \% \\
\mathrm{PD}=-7.22 \% .
\end{gathered}
$$

\section{Discussions of the Results}

The results from the three comparison techniques revealed that biodiesel B20 produced lower torque than that of biodiesel B5, at approximately 7.54\%, 9.14\%, and 7.22\%, as concluded in Table 6 . The results show very comparable results between the conventional technique and the new technique 2 , while the new technique 1 presents an obviously different result.

In order to discuss which techniques can present the reasonable and reliable results, two important technical explanations are addressed as follows. Firstly, biodiesel B5 has an $8.83 \%$ higher heating value than that of biodiesel B20 [16].
TABLE 6: The results from the three comparison techniques.

\begin{tabular}{lcc}
\hline Technique & Result & Interpretations \\
\hline (1) Conventional technique & $-7.54 \%$ & $7.54 \%$ lower than B5 \\
(2) New technique 1 & $-9.14 \%$ & $9.14 \%$ lower than B5 \\
(3) New technique 2 & $-7.22 \%$ & $7.22 \%$ lower than B5 \\
\hline
\end{tabular}

Hence, the output torque of biodiesel B5 should be higher than that of biodiesel B20. All the comparison techniques present the differences in the range between $7.22 \%$ and $9.14 \%$, which are relatively logical.

Secondly, literatures have reported that biodiesel B20 has better lubricating ability and a higher cetane number, which leads to more efficient combustion [17-19]. These benefits can slightly compensate for the poor heating value of biodiesel B20. Consequently, the different output torques between biodiesels B5 and B20 of less than $8.83 \%$ were reliable and expected.

In accordance with the explanation, the new comparison technique 1 revealed a difference of $9.14 \%$, greater than $8.83 \%$, and so it can be reported that the new comparison technique 1 is not an appropriate comparison technique. On the other hand, the conventional technique and the new technique 2 reported the values of $7.54 \%$ and $7.22 \%$, respectively. These two techniques report reasonable and logical results.

The new technique 2 is based on statistical and mathematical procedures. The method can accurately predict a sufficient number of experimental outputs which will lead to more comprehensive, flexible, and accurate results. But the weak point of the new comparison technique 2 regards the complication of its methodology. 


\section{Conclusions and Recommendations}

This research aimed to present the detail of three engine performance comparison techniques, which are (1) "the comparison of the average values (conventional technique)," (2) "the average of the point-to-point comparisons (the new technique 1)," and (3) "the comparison by applying quadratic prediction model (the new technique 2)." The experiment was conducted on a six-cylinder marine engine fuelled with biodiesels B5 and B20. All the comparison techniques reported that biodiesel B20 produced lower torque than that of biodiesel B5. However, further analysis showed that the new technique 1 was an inappropriate comparison technique, while the results from the conventional technique and the new technique 2 were very similar and acceptable.

The contribution of this research is that it provides a new technique for the comparison of engine performance, which can be applied in various fields. The most outstanding benefit of the new technique 2 takes place when it is integrated into the experimental design process. Since the technique can accurately predict the output results in-depth, the number of experiments can be reduced. In other words, this decreases the time and cost usage.

Further investigations on the accuracy of the new technique 2 are also very crucial. The relation of the MPE, MPE, and comparison result should be determined. Furthermore, the maximum values of the MPE and MAPE those still provide an accurate and acceptable comparison result would be specified. The investigation of a number of studies in various fields and statistical analysis is also needed.

\section{Conflict of Interests}

The author declares that there is no conflict of interests regarding the publication of this paper.

\section{References}

[1] A. M. Ashraful, H. H. Masjuki, M. A. Kalam et al., "Production and comparison of fuel properties, engine performance, and emission characteristics of biodiesel from various non-edible vegetable oils: a review," Energy Conversion and Management, vol. 80, pp. 202-228, 2014.

[2] A. Imran, M. Varman, H. H. Masjuki, and M. A. Kalam, "Review on alcohol fumigation on diesel engine: a viable alternative dual fuel technology for satisfactory engine performance and reduction of environment concerning emission," Renewable and Sustainable Energy Reviews, vol. 26, pp. 739-751, 2013.

[3] M. El-Kassaby and M. A. Nemit-Allah, "Studying the effect of compression ratio on an engine fueled with waste oil produced biodiesel/diesel fuel," Alexandria Engineering Journal, vol. 52, no. 1, pp. 1-11, 2013.

[4] P. McCarthy, M. G. Rasul, and S. Moazzem, "Analysis and comparison of performance and emissions of an internal combustion engine fuelled with petroleum diesel and different bio-diesels," Fuel, vol. 90, no. 6, pp. 2147-2157, 2011.

[5] K. Cheenkachorn, C. Poompipatpong, and C. G. Ho, "Performance and emissions of a heavy-duty diesel engine fuelled with diesel and LNG (liquid natural gas)," Energy, vol. 53, pp. 52-57, 2013.
[6] S. B. Han, Y. H. Chang, G. H. Choi, Y. J. Chung, C. Poompipatpong, and S. Koetniyom, "Effect of the intake valve timing and the injection timing for a miller cycle engine," Journal of Energy Engineering, vol. 19, pp. 32-38, 2010.

[7] C. Poompipatpong and A. Kengpol, "A group decision support methodology to weight diesel engine's operating parameters by using analytical hierarchy process and Delphi," International Journal of Industrial Engineering and Technology, vol. 5, pp. 4760, 2013.

[8] N. Maheshwari, C. Balaji, and A. Ramesh, "A nonlinear regression based multi-objective optimization of parameters based on experimental data from an IC engine fueled with biodiesel blends," Biomass \& Bioenergy, vol. 35, no. 5, pp. 2171-2183, 2011.

[9] J. B. Hirkude and A. S. Padalkar, "Performance optimization of CI engine fuelled with waste fried oil methyl ester-diesel blend using response surface methodology," Fuel, vol. 119, pp. 266273, 2014.

[10] H. T. M. Tran, B. Cheirsilp, K. Umsakul, and T. Bourtoom, "Response surface optimisation for acetone-butanol-ethanol production from cassava starch by co-culture of Clostridium butylicum and Bacillus subtilis," Maejo International Journal of Science and Technology, vol. 5, no. 3, pp. 374-389, 2011.

[11] I. Pardoe, Applied Regression Modeling: A Business Approach, John Wiley \& Sons, Hoboken, NJ, USA, 2006.

[12] P. Yenradee, A. Pinnoi, and A. Charoenthavornying, "Demand forecasting and production planning for highly seasonal demand situations: case study of a pressure container factory," ScienceAsia, vol. 27, pp. 271-278, 2001.

[13] A. Poompipatpong, A. Kengpol, and T. Uthistham, "The effects of diesel-waste plastic oil blends on engine performance characteristics," KMUTNB: International Journal of Applied Science and Technology, vol. 7, pp. 37-45, 2014.

[14] N. Udomsri, A. Kengpol, K. Ishii, and Y. Shimada, "The design of a forecasting support models on demand of durian for export markets by time series and ANNs," Asian International Journal of Science and Technology in Production and Manufacturing Engineering, vol. 4, pp. 49-65, 2011.

[15] Y. F. Chang, C. J. Lin, J. M. Chyan, I. M. Chen, and J. E. Chang, "Multiple regression models for the lower heating value of municipal solid waste in Taiwan," Journal of Environmental Management, vol. 85, no. 4, pp. 891-899, 2007.

[16] C. Poompipatpong, N. Krasaelom, P. Triwong, W. Puttavitee, and P. Wongtharua, "An experimental study of performances and emissions in a small fishery boat's engines fuelled with biodiesel B 5 and B 20," The Journal of Industrial Technology, vol. 10, 2014.

[17] D. Altiparmak, A. Keskin, A. Koca, and M. Gürü, "Alternative fuel properties of tall oil fatty acid methyl ester-diesel fuel blends," Bioresource Technology, vol. 98, no. 2, pp. 241-246, 2007.

[18] M. Lapuerta, O. Armas, and J. Rodríguez-Fernández, "Effect of biodiesel fuels on diesel engine emissions," Progress in Energy and Combustion Science, vol. 34, no. 2, pp. 198-223, 2008.

[19] C. Carraretto, A. Macor, A. Mirandola, A. Stoppato, and S. Tonon, "Biodiesel as alternative fuel: experimental analysis and energetic evaluations," Energy, vol. 29, no. 12-15, pp. 2195-2211, 2004 . 


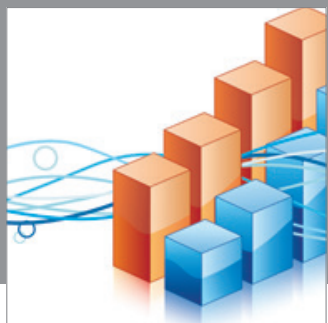

Advances in

Operations Research

mansans

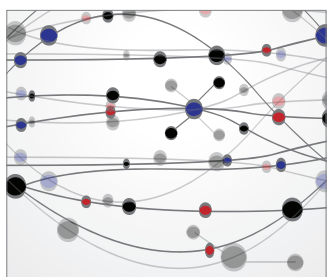

The Scientific World Journal
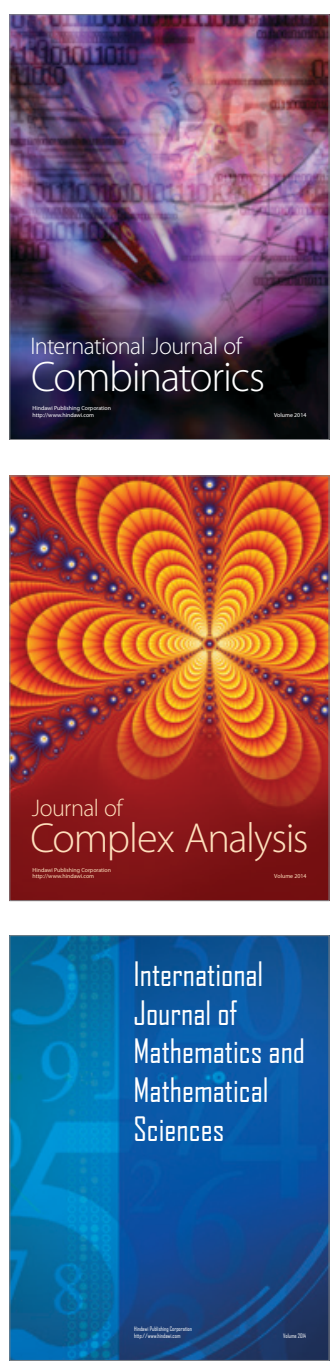
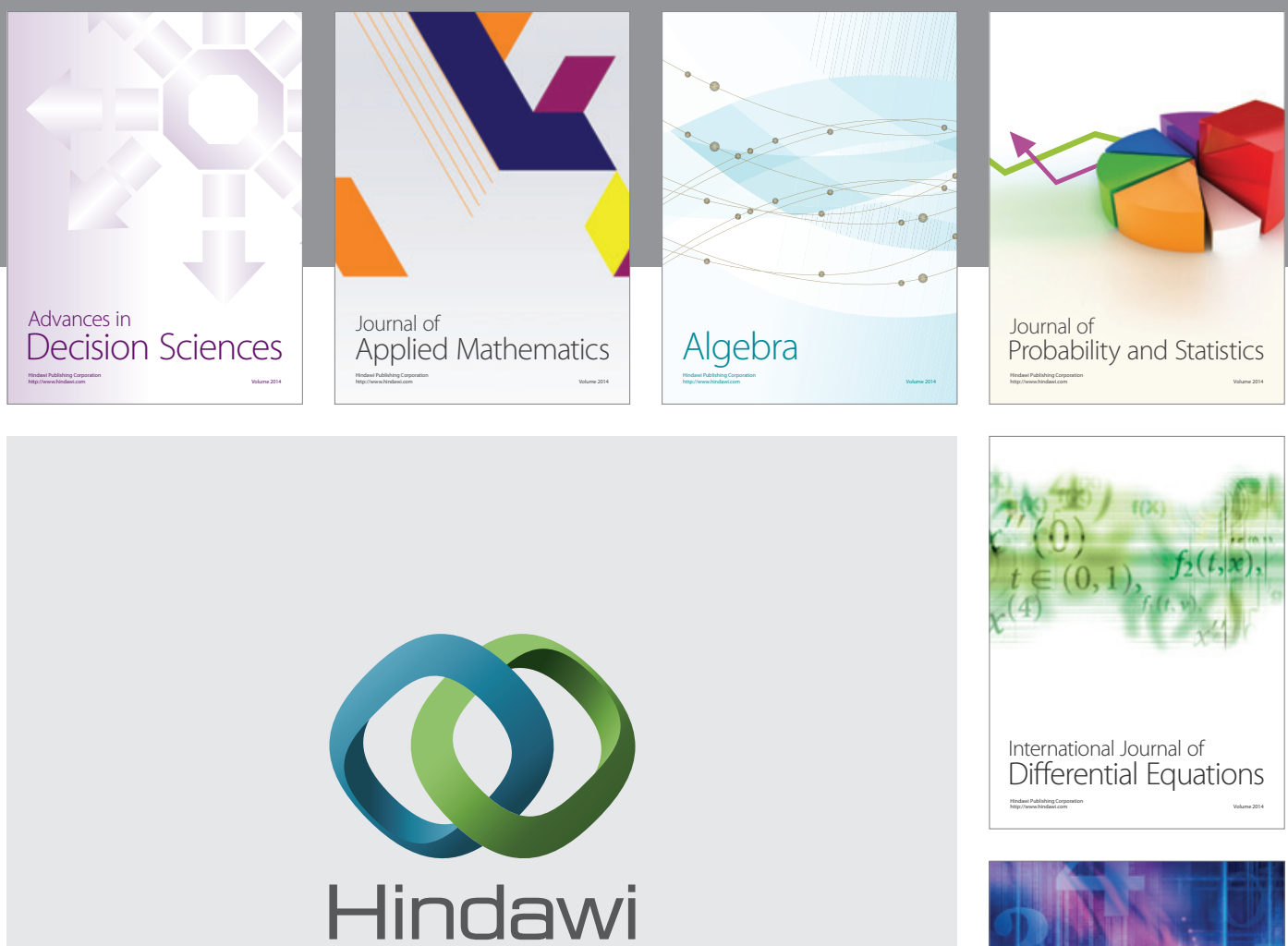

Submit your manuscripts at http://www.hindawi.com
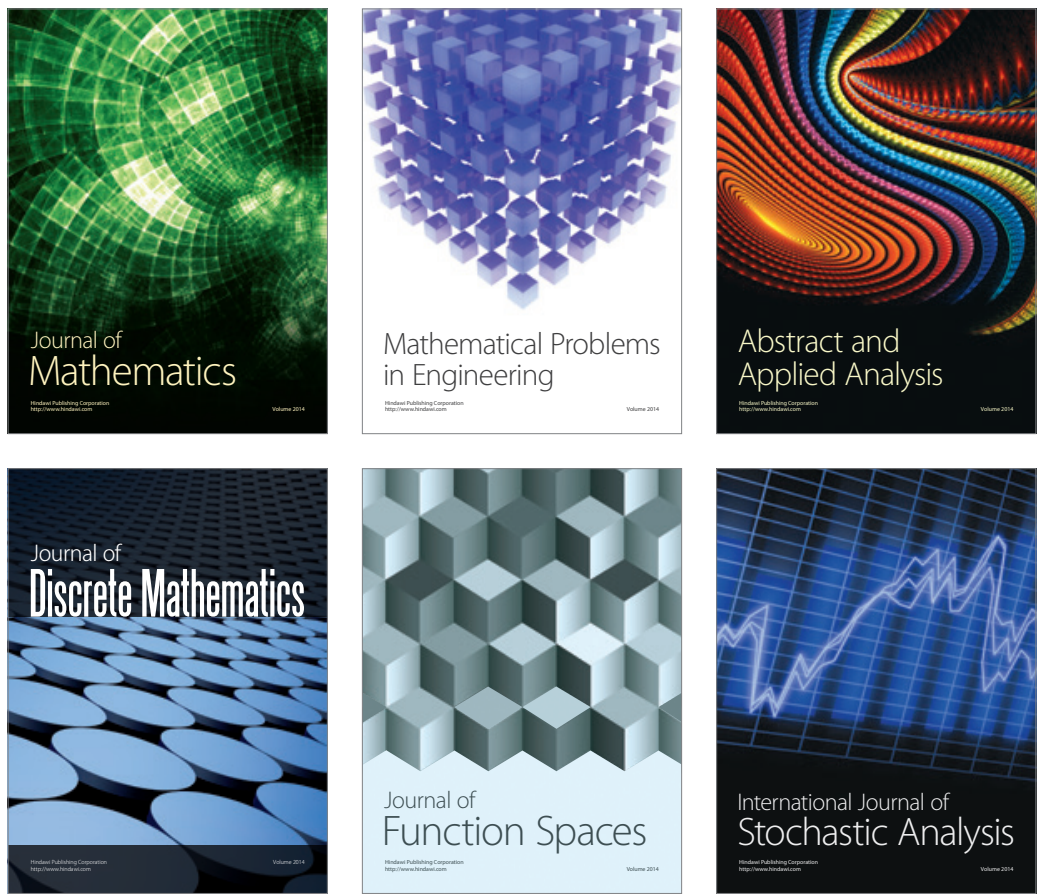

Journal of

Function Spaces

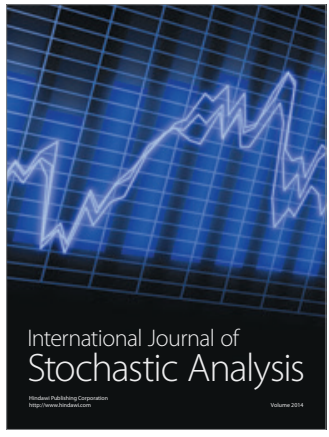

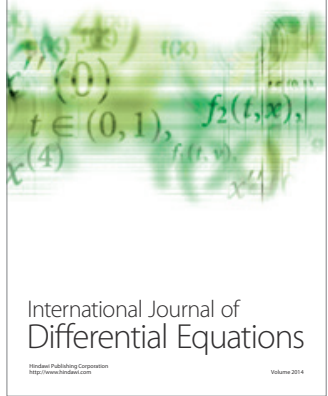
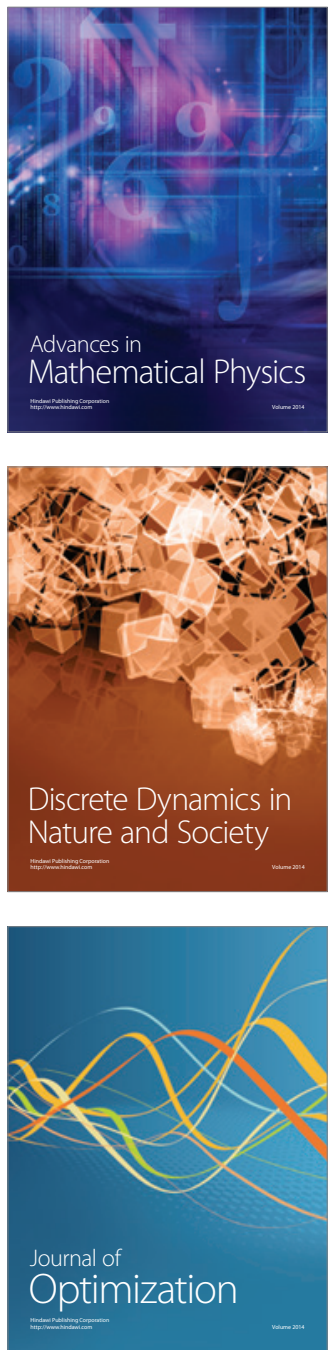